\title{
Update on otitis media - prevention and treatment
}

This article was published in the following Dove Press journal:

Infection and Drug Resistance

10 January 2014

Number of times this article has been viewed

\author{
Ali Qureishi' \\ Yan Lee ${ }^{2}$ \\ Katherine Belfield ${ }^{3}$ \\ John P Birchall ${ }^{4}$ \\ Matija Daniel² \\ 'Otolaryngology Head and Neck \\ Surgery, Northampton General \\ Hospital, Northampton, UK; ${ }^{2}$ NIHR \\ Nottingham Hearing Biomedical \\ Research Unit, Nottingham, UK; \\ ${ }^{3}$ Biomaterials Related Infection \\ Group, ${ }^{4}$ Otorhinolaryngology Head \\ and Neck Surgery, The University \\ of Nottingham, Nottingham, UK
}

Correspondence: Ali Qureishi Clo Matija Daniel

Otolaryngology, Nottingham

University Hospitals, Derby Rd,

Nottingham, NG7 2UH, UK

Tel +44 II59249924 ×61224

Email aliqureishi@doctors.org.uk
Abstract: Acute otitis media and otitis media with effusion are common childhood disorders, a source of significant morbidity, and a leading cause of antibiotic prescription in primary health care. Although effective treatments are available, some shortcomings remain, and thus better treatments would be welcome. Recent discoveries within the field of otitis media research relating to its etiology and pathogenesis have led to further investigation aimed at developing novel treatments. This article provides a review of the latest evidence relating to the understanding of acute otitis media and otitis media with effusion, current treatment strategies, their limitations, new areas of research, and novel strategies for treatment.

Keywords: otitis media, ear, hearing, infection, biofilm, antibiotics

\section{Introduction}

Otitis media (OM) is a group of complex infective and inflammatory conditions affecting the middle ear, with a variety of subtypes differing in presentation, associated complications, and treatment. OM is a leading cause of health care visits worldwide, and its complications are important causes of preventable hearing loss, particularly in the developing world. ${ }^{1}$ This article provides an update on recent scientific achievements within the field of OM research and clinical management.

$\mathrm{OM}$ is pathology of the middle ear and middle ear mucosa, behind the ear drum (tympanic membrane). The middle ear is a cavity containing the ear ossicles (malleus, incus, and stapes), with the eustachian tube placed anteriorly (leading to the nasopharynx), the mastoid air cells posteriorly, tympanic membrane laterally, and the inner ear medially. Other important nearby structures are the brain and meninges superiorly and the sigmoid sinus posteriorly, and any infection of the middle ear can spread to surrounding structures with serious results. The middle ear is lined by modified respiratory epithelium, including ciliated cells and goblet cells; the epithelium produces mucins that are normally transported down the eustachian tube.

Different types of OM present in different ways. ${ }^{2}$ Acute OM (AOM) usually affects children aged under 2 years, and presents with acute onset symptoms and signs of otalgia and fever, in a child that is systemically unwell. It is acute inflammation, and may be caused by bacteria or viruses. A particular subtype of AOM is acute suppurative OM, which is characterized by the presence of pus in the middle ear. If the ear drum perforates (this occurs in approximately 5\%, although higher rates have been reported $)^{3-5}$ then ear discharge will be present also; the perforation usually heals spontaneously. ${ }^{3} \mathrm{AOM}$ is one of the commonest childhood infectious diseases; in the 
majority of cases the disease is self-limiting, ${ }^{6}$ but it has high morbidity, although mortality rates are generally low. ${ }^{7,8}$

A relatively common complication of AOM is acute mastoiditis, defined as acute inflammation of the mastoid periosteum and air cells; this occurs when AOM infection spreads from the middle ear itself into the mastoid air cells and their covering periosteum. The incidence is $1.2-6.0$ in 100,000 and usually occurs in children under 2 years of age. ${ }^{9}$ Patients usually present with the symptoms of AOM plus post-auricular swelling and mastoid tenderness. The condition is more serious than uncomplicated AOM, typically requiring hospital admission, intravenous antibiotics, and surgery if abscess has formed or mastoiditis has not responded to antibiotics.

In contrast to AOM and acute mastoiditis, OM with effusion (OME) is a chronic inflammatory condition. It typically affects children between 3 and 7 years old. It is characterized by the presence of an effusion, glue-like fluid behind an intact tympanic membrane in the absence of signs and symptoms of acute inflammation; ${ }^{10}$ for this reason the commonest reported symptom is hearing loss, which may lead to speech delay or educational problems. Histologically it is a chronic inflammatory condition, characterized by inflammation in the middle ear mucosa, overproduction of mucin and production of altered, more viscous mucin. ${ }^{11}$ Mucin is the predominant component of the middle ear effusion responsible for the thick viscous properties of the "glue;" numerous other components including bacteria have been identified in the middle ear effusion also. ${ }^{11}$

The hearing loss in OME is often transient as the middle ear effusion frequently resolves spontaneously, ${ }^{10}$ especially if OME follows an episode of $\mathrm{AOM} ;{ }^{6}$ when OME is discovered on screening of asymptomatic children, it resolves in $63 \%$ by 3 months and in $88 \%$ by 1 year. ${ }^{6}$ For this reason a "watch and wait" period should be adopted and treatment only offered to those in whom an effusion is persistent. When OME is persistent, particularly if bilateral and early in life, it may impact negatively on speech development, education, and behavior, although the extent to which OME affects these factors and quality of life can be variable and is controversial. ${ }^{10}$

OME has a lower prevalence in adults and is then frequently associated with other underlying diagnoses. Finkelstein et al ${ }^{12}$ described paranasal sinus disease as the dominant factor in $66 \%$ of adults with OME, with other causes including smoking-induced nasopharyngeal lymphoid hyperplasia and adult onset adenoidal hypertrophy in 19\% of cases, and head and neck tumors (mainly nasopharyngeal carcinomas) in $4.8 \%$; in only $1.8 \%$ of patients was no cause identified. For these reasons OME in adults is treated with a greater degree of suspicion, particularly when unilateral. Adults diagnosed with OME should be evaluated for additional underlying conditions and then treated accordingly.

Two additional inflammatory conditions of the middle ear are chronic suppurative OM (CSOM), characterized by the presence of long-standing suppurative middle ear inflammation, usually with a persistently perforated tympanic membrane, and cholesteatoma, which occurs when keratinizing squamous epithelium (skin) is present in the middle ear (normal middle ear is lined by modified respiratory epithelium). Patients with CSOM often experience persistent otorrhea, but this symptom is not obligatory; they can also experience hearing loss, tinnitus, otalgia, and pressure sensation. ${ }^{13}$ The chronic nature of the disease and permanent perforation mean that treatment is usually multifaceted, requiring antimicrobial agents and surgery. Cholesteatoma typically presents with chronic smelly ear discharge, and can be diagnosed when squamous epithelium and keratin are seen in the middle ear; the only curative treatment is surgical.

Although the different types of OM have been described here as discrete diseases with a discrete cluster of clinical symptoms, signs, sequelae, and treatments, in reality there is a great degree of overlap between the different types, so that $\mathrm{OM}$ can be seen as a continuum/spectrum of diseases. AOM, CSOM, and cholesteatoma are also associated with a number of important intracranial and extracranial complications including mastoiditis, meningitis, brain abscess formation, and sigmoid sinus thrombosis; the early detection of these is especially important to limit morbidity and mortality.

\section{Epidemiology}

It is thought that between $50 \%$ and $85 \%$ of children experience at least one episode of AOM by 3 years of age with the peak incidence being between 6 and 15 months. ${ }^{14}$ OME is the commonest cause of hearing impairment in children in the developed world, and can affect as many as $80 \%$ of children at some stage, ${ }^{10,11}$ with approximately 2.2 million new cases of OME annually in the United States of America. ${ }^{15}$

Young children are more prone to AOM and OME due to an anatomical predisposition; the eustachian tube is shorter, more flexible, and horizontal which allows nasopharyngeal pathogens to enter the middle ear with relative ease. In fact nasopharyngeal dimensions have been shown to be smaller in children suffering from repeated attacks of AOM. ${ }^{16}$ The eustachian tube matures by 7 years old; this may explain 
the relative decline in the incidence of $\mathrm{OM}$ after this age. Immaturity of the immune system may also be a contributing factor to AOM.

Certain populations are known to have a higher incidence of OM; eg, Australian Aboriginal children ${ }^{17}$ and children from Greenland. ${ }^{18}$ Other studies have identified numerous potential lifestyle and sociodemographic contributing factors, although a degree of controversy exists regarding the relative importance of the risk factors, as well as their interdependence. These include host risk factors including age $(<5$ years old), male sex, ethnicity (white), low birth weight $(<2.5 \mathrm{~kg})$, premature birth $(<37$ weeks gestation), and pacifier use, as well as environmental factors including season of birth (spring/summer), lack of breastfeeding, day care attendance, number of siblings, parental education/ employment (lower socioeconomic groups), household income (below poverty level), personal and family history of ear infections, and prenatal/postnatal exposure to cigarette smoke. ${ }^{19}$ More recently, atopy ${ }^{20}$ and specific gene abnormalities $\left(T L R 4^{21}\right.$ and $\left.F B X 011^{22}\right)$ have also been implicated as host risk factors for OM.

A recent worldwide systematic review estimated that there are 709 million new cases of AOM annually, with greater than half in children under 5 years of age, and found 31 million new cases of CSOM, with $22.6 \%$ in children under 5 years. ${ }^{1}$ The review also estimated that OM-related hearing impairment was present in 30.82 per 10,000 population, and 21,000 deaths were attributable to OM-related complications. Other worldwide studies have estimated mortality figures as high as 28,000 a year as a result of OM-related complications, mainly due to brain abscesses and meningitis. ${ }^{23}$ Mortality is typically associated with CSOM rather than other types of OM. Thus, it is clear that $\mathrm{OM}$ is not just something that affects quality of life, but has a very real mortality attached to it.

The annual prevalence of OM diagnoses in the United States of America fell by 28\% between 1997 and 2007 from 345 to 247 per 1,000 children, ${ }^{19}$ with the decline attributed to the introduction of the pneumococcal conjugate vaccine, which appears to have decreased the number of individuals suffering from $\mathrm{OM}$ in numerous studies. ${ }^{19,24}$

\section{Etiology}

The etiology of $\mathrm{OM}$ is multifactorial and relates to anatomical variations, pathophysiology including the interaction between microbial agents and host immune response, and cell biology of the middle ear cleft (mastoid, middle ear cavity, eustachian tube) and nasopharynx. ${ }^{25,26}$ Viral upper respiratory tract infections often precede or coincide with episodes of AOM; examples include respiratory syncytial virus, adenovirus, and cytomegalovirus. ${ }^{27}$ Viral infections are now thought to have a pivotal role in AOM progression, and recent randomized controlled trials have demonstrated the role of antiviral treatment for AOM. ${ }^{28}$ It is thought that viral infection of the nasopharynx creates an environment that promotes bacterial colonization, adhesion to cells, and invasion of the middle ear. ${ }^{27}$

The bacteria commonly implicated in upper respiratory tract infections are also those most frequently isolated from middle ear effusions in AOM. These are Streptococcus pneumoniae, Haemophilus influenzae, Moraxella catarrhalis, and to a lesser extent Staphylococcus aureus, and Streptococcus pyogenes; they are believed to enter the middle ear cleft via the eustachian tube. There is a variable incidence in the detection of these bacteria from effusions in AOM, but $S$. pneumoniae and H. influenzae have been detected most frequently in recent studies. ${ }^{29,30}$ Similar bacteria have also been cultured from fluid in OME, although different studies in different circumstances in different countries may produce different findings. In general, the bacteria in OME are similar to those seen in recurrent AOM (RAOM). ${ }^{31}$

Upper respiratory tract infections can lead to mucosal congestion in the eustachian tube and nasopharynx. The resultant congestion prevents normal eustachian tube function and pressure regulation is altered within the middle ear. If sustained, aspiration of nasopharyngeal pathogens can occur into the middle ear. The presence of these pathogens then stimulates inflammation and pus collection within the middle ear, resulting in clinical symptoms of AOM. During this inflammatory period, the middle ear ossicles are less mobile and may be subject to resorption, ${ }^{32}$ which could even lead to permanent conductive hearing loss. Studies have described patients with smaller mastoid cavities as having greater risk of developing chronic middle ear disease, ${ }^{27}$ however, whether this effect is causative is controversial. Patients with chronic infection may also develop sensorineural hearing loss secondary to ototoxicity.

Pathogenesis of AOM is complex and multifactorial. Figure 1 illustrates some of the complex interactions that may lead to AOM development.

OME is histologically a chronic inflammatory condition. An underlying stimulus leads to an inflammatory reaction ${ }^{33}$ with production of more mucin and altered, more viscous mucin types, ${ }^{11}$ which then overwhelms normal mucociliary clearance of the middle ear with functional blockage of the eustachian tube, resulting in the accumulation of a thick, 


\section{Pathophysiology of AOM}

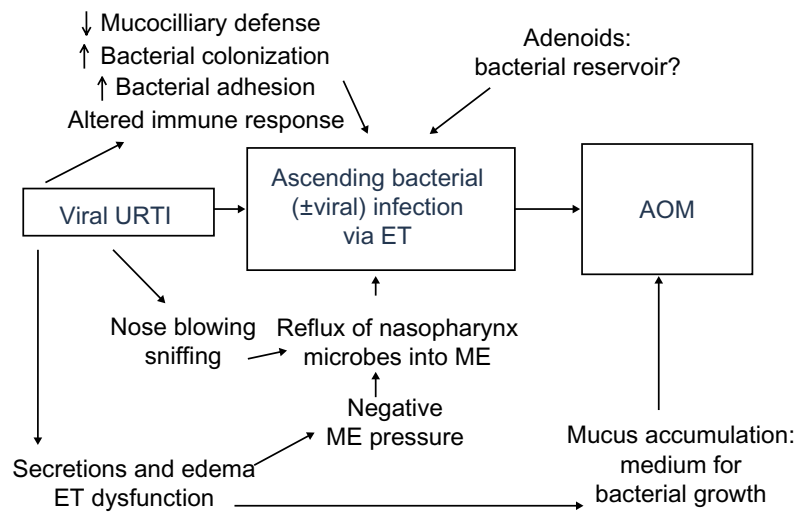

Figure I Pathophysiology of AOM.

Abbreviations: AOM, acute otitis media; ET, eustachian tube; ME, middle ear; URTI, upper respiratory tract infection.

mucin-rich middle ear effusion. ${ }^{26}$ Over the last few years it has become recognized that bacterial biofilms are important in the etiology of OME. ${ }^{34,35}$ These three-dimensional communities of bacteria, attached to a surface, encased in selfproduced extracellular matrix, and with altered phenotype, are thought to exert a chronic inflammatory stimulus leading to OME. Chronic biofilm colonization of the adenoids may act as a reservoir for bacteria entering the middle ear cleft in $\mathrm{OM} \cdot{ }^{36}$ The overexpression of mucin genes is also exacerbated by cigarette smoke. ${ }^{37}$ OME may occur as a consequence of AOM taking an extended period of time to resolve; eg, weeks or months.

Other theories for the development of OME have been postulated. Eustachian tube dysfunction was often thought to cause middle ear effusion through negative pressure in the middle ear cleft; recently, however, a more complex role for the eustachian tube has been described. It is thought to have a role in pressure regulation, secretion clearance, and protection from nasopharyngeal pathogens ${ }^{26}$ Reflux of gastroesophageal acid can also contribute to eustachian tube dysfunction and subsequent $\mathrm{OM} .{ }^{38}$ Genetic factors, including those influencing host immune response also play a role. ${ }^{39}$ The complex interplay of various factors leading to OME is shown in Figure 2.

CSOM typically occurs when chronic middle ear infection prevents the healing of an acute perforation. Cholesteatoma can also result in chronic middle ear infection and inflammation, but the etiology is complex. CSOM is frequently seen in children; in developed countries it is often a result of ventilation tube insertion (ventilation tubes extrude and leave the tympanic membrane perforated), whilst in developing countries CSOM is often a complication of
OME: pathogenesis

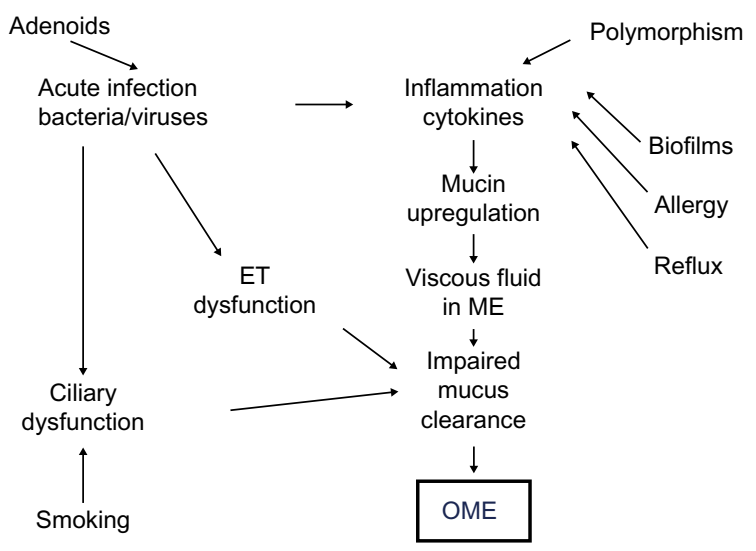

Figure 2 Pathogenesis of OME.

Abbreviations: ET, eustachian tube; ME, middle ear; OME, otitis media with effusion.

AOM with perforation. ${ }^{40}$ Chronic or inadequately treated middle ear infection in the presence of a perforation may allow squamous epithelial migration over the free edges of a perforation, making it permanent. Immunological and genetic factors, in addition to eustachian tube characteristics, play a role in the etiology of CSOM; however, many aspects require further investigation. ${ }^{13}$ Although bacterial cultures are useful in treating drug-resistant organisms, exhaustive studies have established that $90 \%-100 \%$ of chronically discharging ears yield two or greater isolates of aerobic and anaerobic bacteria. ${ }^{23}$

\section{Diagnosis}

Various guidelines exist to aid clinicians in diagnosing $\mathrm{OM}$ and its subtypes. AOM is differentiated from OME and CSOM based on the history and examination findings. Myringotomy (surgical incision of the ear drum) is considered the gold standard for the diagnosis of middle ear fluid; ${ }^{26}$ however, it is not practical to subject every child to this surgical procedure when the diagnosis can be made on the basis of assessment in the clinic.

$\mathrm{AOM}$ is a purulent middle ear process, therefore the signs and symptoms consistent with acute inflammation are present. AOM typically has a short history, and is commonly associated with fever, otalgia, irritability, otorrhea, lethargy, anorexia, and vomiting; the symptoms alone lack sensitivity and specificity for diagnosis. ${ }^{41}$ The American Academy of Pediatrics guidelines ${ }^{42}$ state that AOM should be diagnosed in children with moderate to severe bulging of the tympanic membrane or new onset otorrhea not secondary to otitis externa. The diagnosis may also be made with mild bulging of the tympanic membrane with otalgia or intense tympanic 
membrane erythema; in the absence of a middle ear effusion (assessed with pneumatic otoscopy or tympanometry) the diagnosis is unlikely. Pneumatic otoscopy and tympanometry assess mobility of the ear drum, and if a non-perforated ear drum is immobile this indicates the presence of a middle ear effusion; both techniques rely on varying the ear canal pressure, with pneumatic otoscopy visualizing the ear drum directly and tympanometry assessing mobility by means of sound reflection. If a child has three episodes of AOM within a 6-month period, or four in 1 year, the condition is referred to as RAOM. ${ }^{43}$

OME may occur as a residual effect of AOM, or there may be no preceding history. Clinical features include a history of hearing difficulties, poor attention, behavioral problems, delayed speech and language development, clumsiness, and poor balance. ${ }^{41}$ Otoscopy is vital in making the diagnosis, with sensitivity and specificity quoted at $90 \%$ and $80 \%$, respectively; ${ }^{44}$ this may be increased by using pneumatic otoscopy. The clinical findings are variable, and include abnormal color (eg, yellow/amber/blue), retracted/concave tympanic membrane, and air-fluid levels. Further evidence is obtained with an audiogram (hearing testing typically showing mild conductive hearing loss) and tympanogram (showing an immobile ear drum or negative middle ear pressure). Parental concerns about hearing loss may be unreliable and should not be a substitute for formal audiological investigation. ${ }^{26}$

CSOM is diagnosed when a permanent tympanic perforation is detected alongside middle ear mucositis with or without persistent otorrhea; the discharge should be present for a minimum of 2-6 weeks. ${ }^{40}$ The history is crucial in distinguishing between CSOM, otitis externa, and AOM; in CSOM pain is not usually a predominate feature and ear discharge is likely to be of a longer duration. The diagnosis is confirmed with otoscopy which will usually detect a tympanic membrane perforation and associated middle ear discharge.

\section{Current treatment}

There are well established recommendations for the medical and surgical management of different types of OM. ${ }^{45}$

In general, AOM follows a favorable course without antibiotic treatment, with analgesia and antipyretics being important. Meta-analyses have demonstrated that approximately $80 \%$ of children have spontaneous relief of AOM within 2-14 days. ${ }^{46-48}$ In children aged $<2$ years the results are less clear and resolution may be as low as $30 \%$ in a few days. ${ }^{49}$ The overall high rates of resolution mean that it may be appropriate to simply observe children diagnosed with AOM in the absence of suspected complications.

Current USA guidelines for the treatment of AOM recommend that antibiotics should be used in children aged over 6 months when unilateral or bilateral AOM is severe (moderate to severe otalgia, otalgia lasting at least 48 hours, temperature $39^{\circ} \mathrm{C}$ ). ${ }^{42,50}$ Antibiotics should also be prescribed if AOM is not severe but is bilateral in a child aged 6-23 months. In the case of non-severe unilateral AOM in a child aged 6-23 months, or non-severe unilateral/bilateral AOM in a child aged 24 months or older, antibiotics may be prescribed or observation offered; if observation is chosen, a mechanism should be in place to give antibiotics if symptoms do not improve in 48-72 hours. In addition to assessment of the child's condition, the thoughts of caregivers or parents must be considered and decisions made jointly. Pain assessment and management is an essential aspect of treating AOM. Importantly, an initial period of observation is not associated with a greater risk of complications when compared to those receiving immediate treatment. ${ }^{46}$

The routine prescription of antibiotics for AOM ranges from $31 \%$ in the Netherlands to $98 \%$ in the USA and Australia. ${ }^{41}$ The antibiotic of choice is amoxicillin unless the child has taken this in the past 30 days or is suffering from concurrent purulent conjunctivitis. Antibiotics with additional beta-lactamase cover should be used in these cases or when there is RAOM or a history of AOM unresponsive to amoxicillin. Patient allergies should also be considered and alternative agents used in situations where penicillin allergy exists.

For RAOM, surgically inserted ventilation tubes should be considered if RAOM is associated with a persistent middle ear effusion between AOM attacks. ${ }^{51}$ Prophylactic antibiotics are generally not recommended for RAOM, although a systematic review has noted that they are effective; ${ }^{52}$ due to concerns about long duration of antibiotic exposure and potential side effects, ${ }^{42}$ ventilation tubes generally end up being the preferred option. Both ventilation tubes and prophylactic antibiotics are only effective for the duration of ventilation tube stay time (most ventilation tubes extrude 6-9 months after placement) or for as long as antibiotics are taken, respectively.

As with $\mathrm{AOM}$, many children with $\mathrm{OME}$ do not require treatment due to high rates of spontaneous resolution. However, when OME is bilateral and persistent for more than 3 months, the chances of natural resolution are much lower and treatment may be beneficial. Current UK and USA guidelines ${ }^{50,53}$ recommend a 3 -month period of observation 
with serial audiometry and assessment of the degree of hearing loss and the impact on a child's development before determining the need for treatment, although guidelines are not always followed. ${ }^{54}$ Guidelines recommend either surgery in the form of ventilation tubes or hearing aids. Ventilation tube insertion is associated with a number of risks, which include purulent otorrhea $(10 \%-26 \%)$, myringosclerosis (39\%-65\%), retraction pockets $(21 \%)$, and persistent tympanic membrane perforations $(3 \%$, although with longer-stay T-tubes, up to $24 \%$ ). ${ }^{55}$ In addition, once tubes extrude OME may return, with one trial of short-term tubes noting that $20 \%-25 \%$ of children required a second set of ventilation tubes within 2 years. ${ }^{56}$ Adenoidectomy is also thought to have a role in preventing recurrent $\mathrm{OME},{ }^{57}$ but due to associated risks it is typically not recommended as a primary treatment of OME, unless there are frequent or persistent upper respiratory tract infections. ${ }^{53}$ Numerous other treatments for OME have been trialled, including antibiotics, antihistamines, and steroids, but are not currently recommended. ${ }^{53}$

Unlike AOM and OME, the definitive management for CSOM is usually surgical, ${ }^{13}$ with a variety of techniques described to repair the ear drum and remove infection. Conservative management is appropriate in select patient groups, with the aim of reducing bouts of recurrent discharge and infection and therefore associated hearing loss. ${ }^{58}$ The commonest conservative treatment is regular aural toilet followed by the use of antibiotics, antiseptics, and topical steroids. ${ }^{40}$ Topical quinolones (eg, ciprofloxacin) have been found to be the most effective treatment in a recent Cochrane review, ${ }^{59}$ but although these are licensed in the USA, they are currently not licensed as ear drops in the UK. Many of the frequently used ear drops are based on aminoglycosides, and although concerns exist about their potential ototoxicity when used in the presence of tympanic membrane perforation, the current consensus is that their use is safe in short, supervised courses, and less ototoxic than the infection itself. ${ }^{60}$ Conservative management alone is typically chosen based on patient choice, the absence of surgical options, when the effected side is the only hearing ear, or when the risks of surgery outweigh its benefit.

\section{Emerging strategies in prevention and treatment}

Currently, AOM is a common reason for antibiotic use, and the treatment of OME and AOM with ventilation tube insertion is the commonest cause for surgery in children in the developed world. Yet antibiotic use may lead to emergence of resistance and side effects, whilst ventilation tubes usually require a general anesthetic, extrude after a period of time, and many children need repeat surgery. Better treatment of AOM and OME would therefore be welcome. The ideal treatment would be preventative, effective, immediate, with sustained activity, and nontoxic; current research is focusing on achieving these targets.

\section{Genetics}

The genetic factors resulting in predisposition to $\mathrm{OM}$ are not well understood, although a few genetic targets have been identified. AOM and CSOM heritability estimates of $40 \%-70 \%$ have been reported; however, the majority of genes underlying this susceptibility are yet to be identified. ${ }^{61}$ It is likely that there are mixtures of innate defense molecules which may or may not become defective, leading to OM susceptibility. Potential therapeutic targets are the genes regulating mucin expression, mucus production, and host response to bacteria in the middle ear. ${ }^{39}$ Better understanding of the genetics of OM could also lead to development of preventative measures, or minimization of risk factors in susceptible individuals.

Genetics research has also identified the important role for hypoxia in OME, and this may (partly) explain the effectiveness of ventilation tubes, which would relieve any hypoxia in the middle ear. Mouse models have been used to demonstrate a role for hypoxia inducible factor and vascular endothelial growth factor (HIF-VEGF) signaling pathways in the pathogenesis of OME, and these may be potential future therapeutic targets for the treatment of OME. ${ }^{62}$ Animal models of AOM and OME allow the whole disease process to be analyzed and are subject to experimental manipulation; for these reasons significant efforts have been made to improve the models used to assess this condition; the most recent advances in this field include knock-out mice with spontaneous OM (using MyD88 and TLR2) and induced OM (using TLR2, 4, 9, Trig, dynactin subunit 4) and animal models of bacterial and viral infection. ${ }^{39}$

\section{Pneumococcal vaccine}

Preventative measures for the development of OM are important in limiting the impact of this disease, associated antibiotic prescription, and emerging bacterial resistance. Promising candidate antigens for vaccination have been identified in $S$. pneumoniae (the commonest cause of AOM), nontypeable $H$. influenza, and $M$ catarrhalis. The pneumococcal conjugate vaccine was primarily developed to address invasive pneumococcal disease (ie, pneumonia), but has proven useful in targeting the commonest cause of AOM. ${ }^{63}$ It has therefore attracted a lot of recent attention. 
Numerous systematic reviews have confirmed the efficacy of pneumococcal vaccine in preventing pneumococcal AOM. ${ }^{63,64}$ Following introduction of the 7-valent pneumococcal conjugate vaccine (PCV7), childhood incidence of AOM declined in the USA and Canada. In children aged under 2 years, a $43 \%$ reduction in AOM, $42 \%$ reduction in antibiotic prescription, and $32 \%$ reduction in AOM-related costs has been observed ${ }^{65}$ Canadian studies have shown an overall decline of $25.2 \%$ in AOM from 2000 to 2007, with $13.2 \%$ attributed to the vaccine, and with the largest impact in children under 2 years old. ${ }^{64}$ Significant reductions in nasopharyngeal vaccine serotypes have also been noted after PCV7 introduction. ${ }^{66}$ Whilst PCV7 resulted in the decrease of serotypes covered by the vaccine, pneumococcal serotype 19A increased in carriage and prevalence as an otopathogen ${ }^{67}$ furthermore, isolates of S. pneumoniae serotype 19A resistant to all US Food and Drug Administration (FDA)-approved drugs for use in children to treat AOM have been characterized. ${ }^{68}$

Despite promising results, concerns exist over the long-term benefit from vaccination. A recent study has highlighted concerns regarding increasing incidence of AOM-related complications ${ }^{69}$ Following the introduction of vaccination, AOM-related complications including mastoiditis and other intracranial complications fell; however, they returned to pre-vaccination levels after a few years. ${ }^{69}$ This fall and rise has also been noted in pneumococcal infections from other sites, although in general these infections appear to be less common than they were before vaccination was introduced. ${ }^{70}$ Serotype replacement remains a concern, as does a rise in non-pneumococcal pathogens. ${ }^{69}$

One potential method to overcome vaccine resistance would be to formulate a vaccine from broadly conserved protein antigens; this would be serotype-independent and theoretically not associated with serotype replacement. ${ }^{63}$ This form of vaccine could be more affordable and particularly useful in developing countries, where the need is greatest. ${ }^{71}$ Newer pneumococcal vaccines with protection against additional serotypes have been developed, including the 13-valent pneumococcal vaccine and the 11 -valent pneumococcal polysaccharide conjugate vaccine with protein $\mathrm{D}$ as a carrier, which may also have additional benefit against nontypeable H. influenzae OM. The role of maternal immunization strategies may also be interesting in evaluating benefit to infants.

\section{Developments in microbiology and bacterial resistance}

Widespread use of antibiotics is commonly known to lead to resistance. Antibiotic-induced stress can increase the rate of genetic transformation of $S$. pneumoniae in an effort to generate a resistant phenotype. Furthermore, exposure to sub-minimum-inhibitory-concentration levels of antibiotics increases the pneumococcal mutation rate, which may lead to antibiotic resistance. ${ }^{72}$ Penicillin has traditionally been the antibiotic of choice for $S$. pneumoniae, likewise macrolides and fluoroquinolones are also effective. ${ }^{73}$ The European Centre for Disease Control and Prevention provides antimicrobial resistance surveillance of 27 European countries and shows an overall slight increase in the susceptibility rates of S. pneumoniae to penicillin and macrolides between 2009 and $2011 .^{74,75}$ The data from 2011 show $8.8 \%$ of $S$. pneumoniae isolates were non-susceptible to penicillin and $0.02 \%$ were resistant; additionally, $14.6 \%$ and $14.1 \%$ of pneumococcal isolates were non-susceptible and resistant to macrolides, respectively, and $5.8 \%$ of all isolates were non-susceptible to both. ${ }^{75}$ Resistance to fluoroquinolones has also been demonstrated. ${ }^{72,75}$ Similarly, nontypeable $H$. influenzae, the main serotype responsible for OM, frequently produces beta-lactamase, and is thus resistant to ampicillin; ${ }^{29,76,77}$ amoxicillin/ clavulanate may be preferred, ${ }^{77}$ but a study in Spain found that $13 \%$ of the nontypeable $H$. influenzae isolates were even amoxicillin/clavulanate resistant. ${ }^{29}$

An additional therapeutic problem is the involvement of biofilms in OME. The biofilm mode of growth contributes to persistence through a variety of mechanisms, including phenotypically altered "persister cells" that can repopulate biofilm bacteria ${ }^{78,79}$ defense by the exopolysaccharide matrix, which physically blocks host defense mechanisms, leading to an ineffective inflammatory response; and horizontal gene transfer which can increase virulence. ${ }^{79}$ The high rate of OME reoccurrence, $20 \%-25 \%$ after ventilation tube removal, ${ }^{80}$ could also be explained by biofilm persistence because ventilation tubes remove the effusion but may not necessarily treat the underlying biofilm. ${ }^{56}$ Furthermore, biofilms can develop recalcitrance and resistance to antibiotics. ${ }^{81}$ Biofilm bacteria have a decreased growth rate as compared to the planktonic form, and many antibiotics' target sites are downregulated in this state. The matrix and aggregation of bacteria can physically block antibiotics from reaching some populations in the biofilm at levels above the minimum inhibitory concentration. ${ }^{81}$ Resistance, which differs from recalcitrance in that it results from genetic mutations, can arise due to an increased state of hypermutability ${ }^{82}$ Clinically, this means that biofilm eradication typically requires antibiotic levels that are 10-1,000 times higher than the levels needed to inhibit the planktonic form. ${ }^{83}$ Levels of antibiotics that high would be difficult to safely achieve systemically, but they could be achieved with local drug administration. ${ }^{57}$ 
The understanding that biofilms are important in the pathogenesis of OME opens up the potential for new treatment strategies based on biofilm eradication, including novel methods of delivering antibiotics to the site of infection.

\section{Drug delivery to the middle ear}

Local delivery of antibiotics directly to the ear as a treatment for OM, as opposed to systemic administration, could be an efficient strategy and a safer one in view of the risk of systemic toxicity, especially if a high dose is required. ${ }^{84}$ Broadly speaking, there are two strategies, transtympanic and intratympanic delivery. Transtympanic delivery relies on the possibility of therapeutic molecules diffusing through the ear drum, from the ear canal into the middle ear; this can be facilitated by the use of chemical permeation enhancers. In vivo experiments have shown this to be a promising future strategy, ${ }^{85}$ although it is not currently in clinical use. Therapeutic agents can also be delivered transtympanically as magnetic particles, ${ }^{86}$ but again this is not currently in clinical use as a treatment for OM. A possible major limitation of transtympanic delivery relates to the limited amount of drug that actually can travel across the ear drum.

An alternative is delivery of drugs directly to the middle ear, which would allow a much greater amount of drug to reach the intended site of action. However, the downside is the need to incise or puncture the ear drum in order to achieve drug delivery. A variety of different methods have been proposed, including drug delivery gels ${ }^{87}$ and antibiotic pellets, ${ }^{56}$ with the latter strategy shown to eradicate $S$. aureus biofilms in vitro.

The safety of these administration methods should be assessed prior to widespread clinical use. Any drug, as well as delivery carrier, has the potential to be toxic when delivered directly to the ear in large quantities. Potentially, the middle ear or the inner ear may be affected by toxicity, with effects on hearing and/or balance. Thus, comprehensive toxicity testing is warranted before clinical application.

\section{Conclusion}

$\mathrm{OME}$ and AOM are a significant cause of patient morbidity and cost to the health service. Current guidelines dictate their treatment, but significant shortcomings remain. Recent advances in the fields of microbiology, biofilm study, vaccine developments, genetics, and drug delivery offer the potential for better treatments in the future.

\section{Acknowledgment}

All authors have participated sufficiently to take public responsibility for the content of this article and qualify for authorship in accordance with the journal's guidance.

\section{Disclosure}

The authors report no conflicts of interest in this work.

\section{References}

1. Monasta L, Ronfani L, Marchetti F, et al. Burden of disease caused by otitis media: systematic review and global estimates. PLoS One. 2012;7(4):e36226.

2. Senturia BH, Bluestone CD, Klein JO, et al. Report of the ad hoc committee on definition and classification of OM and OME. Ann Otol Rhinol Laryngol. 1980;89:3-4.

3. Berger G. Nature of spontaneous tympanic membrane perforation in acute otitis media in children. J Laryngol Otol. 1989;103(12):1150-1153.

4. Pukander J. Clinical features of acute otitis media among children. Acta Otolaryngol. 1983;95(1-2):117-122.

5. Kalu SU, Ataya RS, McCormick DP, Patel JA, Revai K, Chonmaitree T. Clinical spectrum of acute otitis media complicating upper respiratory tract viral infection. Pediatr Infect Dis J. 2011;30(2):95-99.

6. Rosenfeld RM, Kay D. Natural history of untreated otitis media. Laryngoscope. 2003;113(10):1645-1657.

7. Venekamp RP, Sanders S, Glasziou PP, Del Mar CB, Rovers MM. Antibiotics for acute otitis media in children [review]. Cochrane Database Syst Rev. 2013;1:CD000219.

8. Stool SE, Field MJ. The impact of otitis media. Pediatr Infect Dis J. 1989;8(Suppl 1):S11-S14.

9. Chesney J, Black A, Choo D. What is the best practice for acute mastoiditis in children? Laryngoscope. Epub July 12, 2013.

10. van Zon A, van der Heijden GJ, van Dongen TM, Burton MJ, Schilder AG. Antibiotics for otitis media with effusion in children [review]. Cochrane Database Syst Rev. 2012;9:CD009163.

11. Kubba H, Pearson JP, Birchall JP. The aetiology of otitis media with effusion: a review. Clin Otolaryngol Allied Sci. 2000;25(3):181-194.

12. Finkelstein Y, Ophir D, Talmi YP, Shabtai A, Strauss M, Zohar Y. Adult onset otitis media with effusion. Arch Otolaryngol Head Neck Surg. 1994;120(5):517-527.

13. Reiss M, Reiss G. [Supparative chronic otitis media: etiology, diagnosis and therapy]. Med Monatsschr Pharm. 2010;33(1):11-16; quiz 17-18. German.

14. Klein JO. Epidemiology of otitis media. Pediatr Infect Dis J. 1989;8(Suppl 1):S9.

15. American Academy of Family Physicians; American Academy of Otolaryngology-Head and Neck Surgery; American Academy of Pediatrics Subcommittee on Otitis Media With Effusion. Otitis media with effusion. Pediatrics. 2004;113(5):1412-1429.

16. Renko M, Kristo A, Tapiainen T, et al. Nasopharyngeal dimensions in magnetic resonance imaging and the risk of acute otitis media. J Laryngol Otol. 2007;121(9):853-856.

17. Coates HL, Morris PS, Leach AJ, Couzos S. Otitis media in Aboriginal children: tackling a major health problem. Med J Aust. 2002;177(4): 177-178.

18. Koch A, Homøe P, Pipper C, Hjuler T, Melbye M. Chronic suppurative otitis media in a birth cohort of children in Greenland: populationbased study of incidence and risk factors. Pediatr Infect Dis J. 2011;30(1):25-29.

19. Hoffman HJ, Daly KA, Bainbridge KE, et al. Panel 1: Epidemiology, natural history, and risk factors. Otolaryngol Head Neck Surg. 2013;148(Suppl 4):E1-E25.

20. MacIntyre EA, Heinrich J. Otitis media in infancy and development of asthma and atopic disease. Curr Allergy Asthma Rep. 2012;12(6): $547-550$. 
21. Macarthur CJ, Wilmot B, Wang L, Schuller M, Lighthall J, Trune D. Genetic susceptibility to chronic otitis media with effusion: Candidate gene single nucleotide polymorphisms. Laryngoscope. Epub August 8, 2013.

22. Rye MS, Wiertsema SP, Scaman ES, et al. FBXO11, a regulator of the TGF $\beta$ pathway, is associated with severe otitis media in Western Australian children. Genes Immun. 2011;12(5):352-359.

23. World Health Organization. Chronic Suppurative Otitis Media. Burden of Illness and Management Options. Geneva: World Health Organization, 2004. Available from: http://www.who.int/pbd/deafness/activities/ hearing_care/otitis_media.pdf. Accessed November 25, 2013.

24. Fletcher MA, Fritzell B. Pneumococcal conjugate vaccines and otitis media: an appraisal of the clinical trials. Int $J$ Otolaryngol. 2012;2012:312935.

25. Cayé-Thomasen P, Hermansson A, Bakaletz L, et al. Panel 3: Recent advances in anatomy, pathology, and cell biology in relation to otitis media pathogenesis. Otolaryngol Head Neck Surg. 2013;148(Suppl 4): E37-E51.

26. Rovers MM, Schilder AG, Zielhuis GA, Rosenfeld RM. Otitis media. Lancet. 2004;363(9407):465-473.

27. Murphy TF, Chonmaitree T, Barenkamp S, et al. Panel 5: Microbiology and immunology panel. Otolaryngol Head Neck Surg. 2013;148(Suppl 4):E64-E89.

28. Heinonen S, Silvennoinen H, Lehtinen P, et al. Early oseltamivir treatment of influenza in children 1-3 years of age: a randomized controlled trial. Clin Infect Dis. 2010;51(8):887-894.

29. Pumarola F, Marès J, Losada I, et al. Microbiology of bacteria causing recurrent acute otitis media (AOM) and AOM treatment failure in young children in Spain: shifting pathogens in the post-pneumococcal conjugate vaccination era. Int J Pediatr Otorhinolaryngol. 2013;77(8):1231-1236.

30. Chen YJ, Hsieh YC, Huang YC, Chiu CH. Clinical manifestations and microbiology of acute otitis media with spontaneous otorrhoea in children. J Microbiol Immunol Infect. 2013;46(5):382-388.

31. Stol K, Verhaegh SJ, Graamans K, et al. Microbial profiling does not differentiate between childhood recurrent acute otitis media and chronic otitis media with effusion. Int $J$ Pediatr Otorhinolaryngol. 2013;77(4):488-493.

32. Salomonsen RL, Hermansson A, Cayé-Thomasen P. Ossicular bone modeling in acute otitis media. Otol Neurotol. 2010;31(7):1109-1114.

33. MacArthur CJ, Pillers DA, Pang J, Kempton JB, Trune DR. Altered expression of middle ear inner ear cytokines in mouse otitis media. Laryngoscope. 2011;121(2):365-371.

34. Hall-Stoodley L, Hu FZ, Gieseke A, et al. Direct detection of bacterial biofilms on the middle-ear mucosa of children with chronic otitis media JAMA. 2006;12;296(2):202-211.

35. Daniel M, Imtiaz-Umer S, Fergie N, Birchall JP, Bayston R. Bacterial involvement in otitis media with effusion. Int $J$ Pediatr Otorhinolaryngol. 2012;76(10):1416-1422.

36. Saafan ME, Ibrahim WS, Tomoum MO. Role of adenoid biofilm in chronic otitis media with effusion in children. Eur Arch Otorhinolaryngol. 2013;270(9):2417-2425.

37. Preciado D, Kuo E, Ashktorab S, Manes P, Rose M. Cigarette smoke activates NFKB-mediated Tnf- $\alpha$ release from mouse middle ear cells. Laryngoscope. 2010;120(12):2508-2515.

38. Tasker A, Dettmar PW, Panetti M, Koufman JA, Birchall JP, Pearson JP. Reflux of gastric juice and glue ear in children. Lancet. 2002;359(9305):493

39. Li JD, Hermansson A, Ryan AF, et al. Panel 4: Recent advances in otitis media in molecular biology, biochemistry, genetics, and animal models. Otolaryngol Head Neck Surg. 2013;148(Suppl 4):E52-E63.

40. Marchisio P, Chonmaitree T, Leibovitz E, et al. Panel 7: Treatment and comparative effectiveness research. Otolaryngol Head Neck Surg. 2013;148(Suppl 4):E102-E121.

41. Scottish Intercollegiate Guidelines Network. Guidelines No 66 Diagnosis and Management of Childhood Otitis Media in Primary Care. Edinburgh: Royal College of Physicians; 2003. Available from: http://www.sign.ac.uk/pdf/qrg66.pdf. Accessed October 30, 2013
42. Lieberthal AS, Carroll AE, Chonmaitree T, et al. The diagnosis and management of acute otitis media. Pediatrics. 2013;131(3):e964-e999.

43. Whittemore KR Jr. What is the role of tympanostomy tubes in the treatment of recurrent acute otitis media? Laryngoscope. 2013; 123(1):9-10.

44. Bluestone CD, Cantekin EI. Design factors in the characterization and identification of otitis media and certain related conditions. Ann Otol Rhinol Laryngol Suppl. 1979;88(5 Pt 2 Suppl 60):13-28.

45. To K, Harrison L, Daniel M. Management of otitis media with effusion and recurrent acute otitis media. The Otorhinolaryngologist. In press 2013.

46. Marcy M, Takata G, Shekelle P, et al. Management of Acute Otitis Media. Evidence Report/Technology Assessment No 15. Rockville, MD: Agency for Healthcare Research and Quality; 2001.

47. Glasziou PP, Del Mar CB, Sanders SL, Hayem M. Antibiotics for acute otitis media in children [review]. Cochrane Database Syst Rev. 2004;(1):CD000219

48. Rosenfeld RM, Vertrees JE, Carr J, et al. Clinical efficacy of antimicrobial drugs for acute otitis media: metaanalysis of 5400 children from thirty-three randomized trials. J Pediatr. 1994;124(3):355-367.

49. Damoiseaux RA, van Balen FA, Hoes AW, Verheij TJ, de Melker RA. Primary care based randomised double blind trial of amoxicillin versus placebo for acute otitis media in children aged under 2 years. $B M J$. 2000;320(7231):350-354

50. American Academy of Pediatrics Subcommittee on Management of Acute Otitis Media. Diagnosis and management of acute otitis media. Pediatrics. 2004;113(5):1451-1465.

51. Rosenfeld RM, Schwartz SR, Pynnonen MA, et al. Clinical practice guideline: Tympanostomy tubes in children. Otolaryngol Head Neck Surg. Jul 2013;149(Suppl 1):S1-S35.

52. Leach AJ, Morris PJ. Antibiotics for the prevention of acute and chronic suppurative otitis media in children [review]. Cochrane Database Syst Rev. 2006;(4):CD004401.

53. Surgical management of children with otitis media with effusion (OME) [webpage on the Internet]. London: National Institute for Health and Clinical Excellence; 2008 [updated May 30, 2012]. Available from: http://guidance.nice.org.uk/CG60. Accessed October 30, 2013.

54. Daniel M, Kamani T, El-Shunnar S, et al. National Institute for Clinical Excellence guidelines on the surgical management of otitis media with effusion: are they being followed and have they changed practice? Int $J$ Pediatr Otorhinolaryngol. 2013;77(1):54-58.

55. Vlastarakos PV, Nikolopoulos TP, Korres S, Tavoulari E, Tzagaroulakis A, Ferekidis E. Grommets in otitis media with effusion: the most frequent operation in children. But is it associated with significant complications? Eur J Pediatr. 2007;166(5):385-391.

56. Daniel M, Chessman R, Al-Zahid S, et al. Biofilm eradication with biodegradable modified-release antibiotic pellets: a potential treatment for glue ear. Arch Otolaryngol Head Neck Surg. 2012;138(10): 942-949.

57. van den Aardweg MT, Schilder AG, Herkert E, Boonacker CW, Rovers MM. Adenoidectomy for otitis media in children [review]. Cochrane Database Syst Rev. 2010;(1):CD007810.

58. Woodfield G, Dugdale A. Evidence behind the WHO guidelines: hospital care for children: what is the most effective antibiotic regime for chronic suppurative otitis media in children? J Trop Pediatr. 2008;54(3):151-156.

59. Macfadyen CA, Acuin JM, Gamble C. Systemic antibiotics versus topical treatments for chronically discharging ears with underlying eardrum perforations [review]. Cochrane Database Syst Rev. 2006;(1): CD005608.

60. Phillips JS, Yung MW, Burton MJ, Swain IR. Evidence review and ENT-UK consensus report for the use of aminoglycoside-containing ear drops in the presence of an open middle ear. Clin Otolaryngol. 2007;32(5):330-336.

61. Rye MS, Bhutta MF, Cheeseman MT, et al. Unraveling the genetics of otitis media: from mouse to human and back again. Mamm Genome. 2011;22(1-2):66-82. 
62. Cheeseman MT, Tyrer HE, Williams D, et al. HIF-VEGF pathways are critical for chronic otitis media in Junbo and Jeff mouse mutants. PLoS Genet. 2011;7(10):e1002336.

63. Pelton SI, Pettigrew MM, Barenkamp SJ, et al. Panel 6: Vaccines. Otolaryngol Head Neck Surg. 2013;148(Suppl 4):E90-E101.

64. Wals PD, Carbon M, Sévin E, Deceuninck G, Ouakki M. Reduced physician claims for otitis media after implementation of pneumococcal conjugate vaccine program in the province of Quebec, Canada. Pediatr Infect Dis J. 2009;28(9):e271-e275.

65. Zhou F, Shefer A, Kong Y, Nuorti JP. Trends in acute otitis mediarelated health care utilization by privately insured young children in the United States, 1997-2004. Pediatrics. 2008;121(2):253-260.

66. Siber GR, Klugman KP, Mäkelä PH. Nasopharyngeal carriage. In: Siber GR, Klugman KP, Mäkelä PH, editors. Pneumococcal Vaccines: The Impact of Conjugate Vaccine. Washington, DC: ASM Press; 2008:279-300.

67. Dunne EM, Smith-Vaughan HC, Robins-Browne RM, Mulholland EK, Satzke C. Nasopharyngeal microbial interactions in the era of pneumococcal conjugate vaccination. Vaccine. 2013;31(19):2333-2342.

68. Pichichero ME, Casey JR. Emergence of a multiresistant serotype 19A pneumococcal strain not included in the 7-valent conjugate vaccine as an otopathogen in children. JAMA. 2007;298(15):1772-1778.

69. Daniel M, Gautam S, Scrivener TA, Meller C, Levin B, Curotta J. What effect has pneumococcal vaccination had on acute mastoiditis? J Laryngol Otol. 2013;127 Suppl 1:S30-S34.

70. Zangeneh TT, Baracco G, Al-Tawfiq JA. Impact of conjugate pneumoccal vaccines on the changing epidemiology of pneumococcal infections. Expert Rev Vaccines. 2011;10(3):345-353.

71. Levine OS, Cherian T, Hajjeh R, Knoll MD. Progress and future challenges in coordinated surveillance and detection of pneumococcal and Hib disease in developing countries. Clin Infect Dis. 2009;48 Suppl 2:S33-S36.

72. Cornick JE, Bentley SD. Streptococcus pneumoniae: The evolution of antimicrobial resistance to beta-lactams, fluoroquinolones, and macrolides. Microbes Infect. 2012;14(7-8):573-583.

73. Kaplan SL, Mason EO Jr. Management of infections due to antibiotic-resistant Streptococcus pneumoniae. Clin Microbiol Rev. 1998;11(4):628-644.

74. European Centre for Disease Prevention and Control. Antimicrobial resistance surveillance in Europe 2009. Annual Report of the European Antimicrobial Resistance Surveillance Network (EARS-Net). Stockholm: European Centre for Disease Prevention and Control; 2010. Available from: http://www.ecdc.europa.eu/en/publications/Publications/1011_ SUR_annual_EARS_Net_2009.pdf. Accessed November 25, 2013.
75. European Centre for Disease Prevention and Control. Antimicrobial resistance surveillance in Europe 2011. Annual Report of the European Antimicrobial Resistance Surveillance Network (EARS-Net). Stockholm: European Centre for Disease Prevention and Control; 2012. Available from: http://www.ecdc.europa.eu/en/publications/publications/antimicrobial-resistance-surveillance-europe-2011.pdf. Accessed November 25, 2013.

76. Sommerfleck P, González Macchi ME, Pellegrini S, et al. Acute otitis media in infants younger than three months not vaccinated against Streptococcus pneumoniae. Int J Pediatr Otorhinolaryngol. 2013;77(6): 976-980.

77. Pichichero ME. Otitis media. Pediatr Clin North Am. 2013;60(2): 391-407.

78. Lewis K. Persister cells: molecular mechanisms related to antibiotic tolerance. Handb Exp Pharmacol. 2012;(211):121-133.

79. Seth AK, Geringer MR, Hong SJ, Leung KP, Mustoe TA, Galiano RD. In vivo modeling of biofilm-infected wounds: a review. J Surg Res. 2012;178(1):330-338.

80. Gates GA, Avery CA, Prihoda TJ, Cooper JC Jr. Effectiveness of adenoidectomy and tympanostomy tubes in the treatment of chronic otitis media with effusion. $N$ Engl J Med. 1987;317(23): 1444-1451.

81. Stewart PS, Costerton JW. Antibiotic resistance of bacteria in biofilms. Lancet. 2001;358(9276):135-138.

82. Ryder VJ, Chopra I, O’Neill AJ. Increased mutability of staphylococci in biofilms as a consequence of oxidative stress. PLoS One. 2012;7(10): e47695.

83. Donlon RM, Costerton JW. Biofilms: survival mechanisms of clinically relevant microorganisms. Clin Microbiol Rev. 2002;15(2):167-193.

84. Hoskison E, Daniel M, Al-Zahid S, Shakesheff KM, Bayston R, Birchall JP. Drug delivery to the ear. Ther Deliv. 2013;4(1):115-124.

85. Khoo X, Simons EJ, Chiang HH, et al. Formulations for trans-tympanic antibiotic delivery. Biomaterials. 2013;34(4):1281-1288.

86. Sarwar A, Nemirovski A, Shapiro B. Optimal Halbach permanent magnet designs for maximally pulling and pushing nanoparticles. J Magn Magn Mater. 2012;324(5):742-754.

87. Jang $\mathrm{CH}$, Park $\mathrm{H}, \mathrm{Cho} \mathrm{YB}, \mathrm{Choi} \mathrm{CH}$. The effect of anti-adhesive packing agents in the middle ear of guinea pig. Int J Pediatr Otorhinolaryngol. 2008;72(11):1603-1608.
Infection and Drug Resistance

\section{Publish your work in this journal}

Infection and Drug Resistance is an international, peer-reviewed openaccess journal that focuses on the optimal treatment of infection (bacterial, fungal and viral) and the development and institution of preventive strategies to minimize the development and spread of resistance. The journal is specifically concerned with the epidemiology of antibiotic

\section{Dovepress}

resistance and the mechanisms of resistance development and diffusion in both hospitals and the community. The manuscript management system is completely online and includes a very quick and fair peerreview system, which is all easy to use. Visit http://www.dovepress.com/ testimonials.php to read real quotes from published authors. 